\title{
Picosecond supercontinuum generation with back seeding of different spectral parts
}

\author{
Moselund, Peter Morten; Frosz, Michael Henoch; Thomsen, C.L.; Bang, Ole
}

Published in:

Joint Conference of the Opto-Electronics and Communications Conference and the Australian Conference on Optical Fibre Technology

Link to article, DOI:

10.1109/OECCACOFT.2008.4610474

Publication date:

2008

Document Version

Publisher's PDF, also known as Version of record

Link back to DTU Orbit

Citation (APA):

Moselund, P. M., Frosz, M. H., Thomsen, C. L., \& Bang, O. (2008). Picosecond supercontinuum generation with back seeding of different spectral parts. In Joint Conference of the Opto-Electronics and Communications Conference and the Australian Conference on Optical Fibre Technology (pp. 1-2). IEEE. https://doi.org/10.1109/OECCACOFT.2008.4610474

\section{General rights}

Copyright and moral rights for the publications made accessible in the public portal are retained by the authors and/or other copyright owners and it is a condition of accessing publications that users recognise and abide by the legal requirements associated with these rights.

- Users may download and print one copy of any publication from the public portal for the purpose of private study or research.

- You may not further distribute the material or use it for any profit-making activity or commercial gain

- You may freely distribute the URL identifying the publication in the public portal 


\title{
Picosecond supercontinuum generation with back seeding of different spectral parts
}

\author{
Peter M. Moselund ${ }^{1,2}$, Michael H. Frosz ${ }^{1,2}$ Carsten L. Thomsen ${ }^{2}$, and Ole Bang ${ }^{1}$ \\ ${ }^{1}$ DTU Fotonik, Dept. of Photonics Engineering, Technical University of Denmark, DK-2800 Kgs. Lyngby, Denmark \\ ${ }^{2}$ Koheras A/S, Blokken 84, DK-3460, Birkerød, Denmark \\ Phone: +45 45256373, Fax: +45 45936581, Email: bang@,com.dtu.dk
}

\begin{abstract}
We study supercontinuum generation with picosecond pumping and the spectrum obtained when coupling back the part of the output around 1200-1700 nanometres or the part around 700-900 nanometres with a variable time delay.
\end{abstract}

\section{Introduction}

A decade has passed since the introduction of photonic crystal fibres (PCFs), which made it possible to produce a supercontinuum (SC) with relatively low peak power. In this time, there has been great activity in research related to $\mathrm{SC}$ generation. The basic processes that generate and limit the SC are now mostly understood and focus has shifted toward specializing the SC toward particular applications such as fluorescence microscopy [1] or optical coherence tomography (OCT) [2, 3]. The focus of SC research has now shifted to how the generated spectrum can be controlled and tailored to fit particular applications. One branch of this research centres on how one can produce tuneable peaks in the $\mathrm{SC}$. The most successful solutions to this problem to date have been based on utilizing gratings for phase matching control $[4,5]$ or peak generation by four-wave mixing (FWM) $[6,7]$.

Here we demonstrate a new method by which a tuneable peak can be produced in an SC spectrum. In order to produce this peak we feed back part of the SC and time match it with the pump pulses. The interaction between the pump pulse and the part of the output which has been fed back greatly changes the output spectrum as can be seen in fig. 1 .

\section{Experimental setup}

The SC was generated in $4 \mathrm{~m}$ of 1050-Zero-2 fibre, commercially available from Crystal Fibre A/S. A diagram of the measurement setup can be seen in fig. 2 .

The SC was pumped at $1064 \mathrm{~nm}$ with $13.4 \mathrm{ps}$ pulses with a pulse repetition frequency of $70 \mathrm{MHz}$ and an average power of $120 \mathrm{~mW}$. The pump system was based on a custom made polarisation-maintaining modelocked ytterbium doped fibre laser. The laser was amplified in 2 amplifiers based on ytterbium doped single mode fibre and finally in a double clad high-power amplifier.

The output from the amplifier had a random polarisation which was converted to linear polarization using a $\lambda / 4$ and $\lambda / 2$ waveplate before being passed through a linearly polarised free space isolator. Beyond the isolator, the orientation of the pump polarisation relative to the fibre structure is controlled using another $\lambda / 2$ waveplate. The light is coupled into the PCF with a coupling efficiency of $50 \%$ using an achromatic lens.

The output spectrum of the PCF is sampled using a $10 \%$ beam splitter whose reflection is collected by a fibre and analyzed using an optical spectrum analyser (OSA).

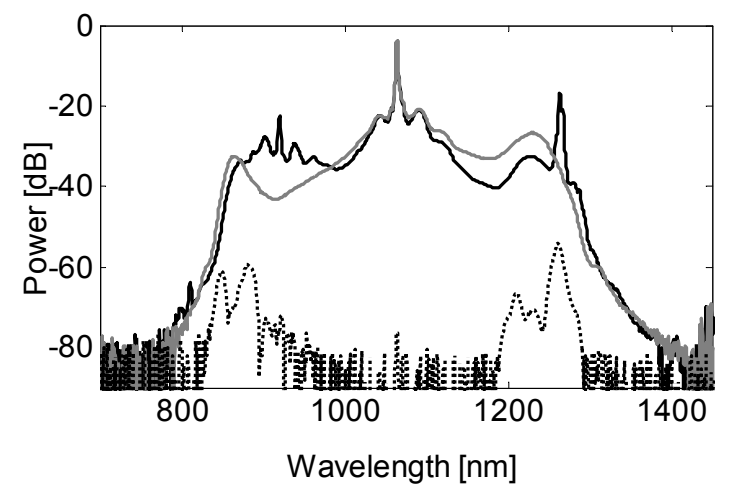

Fig. 1. Spectrum of the supercontinuum without (gray solid) and with (black solid) feedback and the feedback itself (black dotted).

In order to produce a feedback effect, the PCF is mounted between two mirrors as in a Fabry-Perot cavity. Mirror 6 (see fig. 2) is a spectrally flat silver mirror while the reflection spectrum of mirror 10 is used to control which part of the spectrum is fed back. The reflection shown in fig. 1 is the reflection present when a mirror with high reflectance at $1200-1700 \mathrm{~nm}$ is used. The multi-peaked structure of the feedback spectrum in the area $1200-1300 \mathrm{~nm}$ is due to ripples in the transmission of the $45^{\circ} 1064 \mathrm{~nm}$ (pump wavelength) mirrors. The light in the $850-950 \mathrm{~nm}$ region is reflected because the 1200-1700 nm mirror does not have an anti reflex coating for these wavelengths.

The length of the Fabry-Perot cavity is adjusted so that its round trip time exactly matches a whole number of periods of the pump pulse train. The light which is fed back will therefore enter the input of the PCF together with the pump pulse so that they can interact as they propagate through the PCF.

\section{Results}

As can be seen in fig. 1, the addition of feedback greatly modifies the spectrum of the generated SC.

The strong peak generated at $1270 \mathrm{~nm}$, when feedback is present, corresponds to the strongest peak in the 


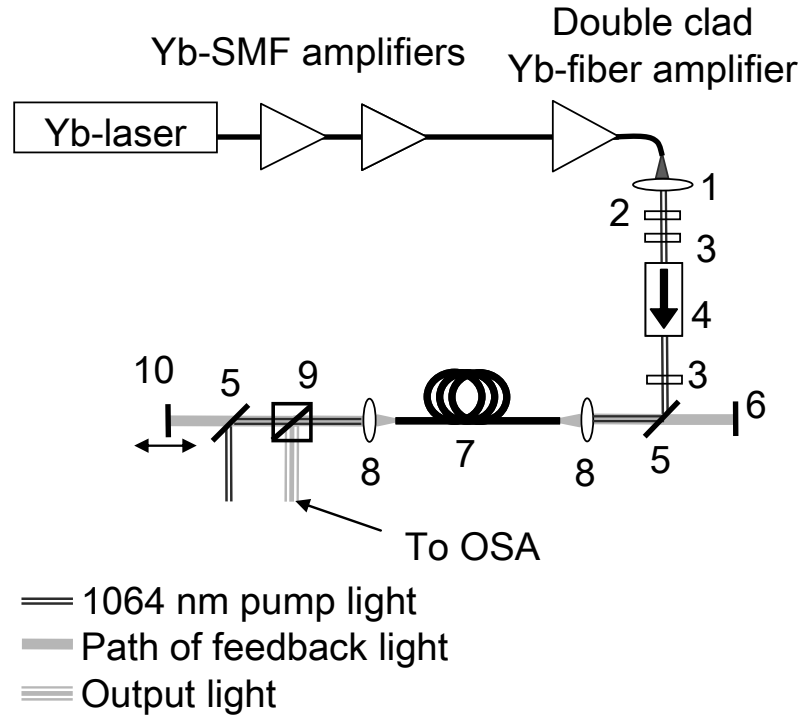

Fig. 2. Measurement setup. 1 Lens $\mathrm{f}=4.5 \mathrm{~mm}, 2 \lambda / 4$ waveplate, $3 \lambda / 2$ waveplate, 4 Optical isolator, $51064 \mathrm{~nm} 45^{\circ}$ mirror, $6 \mathrm{Ag}$ mirror, 7 PCF-fibre, 8 Achromatic lens with $\mathrm{f}=4.5 \mathrm{~mm}, 9$ Beam splitter, and 10 control mirror

feedback. This indicates that the position of the peak is controlled by the feedback mirror and thus that it can be tuned by tuning the spectrum of the feedback. The sum of the frequencies of the $1270 \mathrm{~nm}$ and the $924 \mathrm{~nm}$ peaks is just $0.5 \%$ less than twice the frequency of the pump. This indicates that the peaks could be created by a parametric gain process with the pump, as their frequencies live up to the requirement of energy conservation through such processes. The two smaller peaks at 903 and $938 \mathrm{~nm}$ similarly fit with FWM between the $1270 \mathrm{~nm}$ peak, the pump and the pump side peaks at 1035 and $1095 \mathrm{~nm}$.

Fibres similar to the one used here have previously [8] been shown to have two pairs of FWM phase matching wavelengths. The exact position of the pairs of matching wavelength is very sensitive to the variations in the dispersion curve caused by small variations in the fibre, created during the drawing process. However, these two pairs of FWM matching wavelengths could correspond to the peaks at 1035 and $1095 \mathrm{~nm}$ and the peaks at 923 and $1270 \mathrm{~nm}$ respectively.

The feedback was tested using a control mirror with high reflection at 1200-1700 $\mathrm{nm}$. It mainly fed back the long wavelength light, as can be seen in fig. 1. We also tested the system using a mirror with a broad reflection centred at $870 \mathrm{~nm}$. This mirror mainly fed back the short wavelength part of the spectrum, but this did not increase the amount of light generated at the short wavelengths in the output SC. Instead, both the peak at $1270 \mathrm{~nm}$ and the peaks around $900 \mathrm{~nm}$ were reduced.

This shows that the peak generation process is only dependent on light being fed back at the long wavelengths and that strengthening of the spectrum at $850-950 \mathrm{~nm}$ can only take place when the pump can create FWM with light at $1270 \mathrm{~nm}$.
Additionally, we investigated the effect of varying the delay of the feedback light and found that the strong peak at $1270 \mathrm{~nm}$ disappeared if the delay was changed more than $+/-2$ ps. This shows that the generation of the strong peak is dependent on good time matching with the feedback light.

\section{Conclusions}

We have demonstrated a new method which can be used to modify the output spectrum of an SC source significantly. It can both be used to amplify the spectrum by $18 \mathrm{~dB}$ in a narrow region, e.g. at $1270 \mathrm{~nm}$ in fig. 1 , and to produce an increase in a wide region of over 100 $\mathrm{nm}$, e.g. in the $850-950 \mathrm{~nm}$ region on fig. 1. This means that time matched spectral feedback is a very powerful method for modifying an SC spectrum.

The position of the strongest peak generated in the output corresponds to the wavelength of the strongest feedback and this indicates that the position of the peak can be changed by controlling which wavelength is fed back into the PCF.

This effect has been shown experimentally using long picosecond pulses unlike many earlier spectral shaping methods, which have only been demonstrated using more complicated femtosecond lasers. This means that this method is more easily adaptable for commercial SC sources which generally use picosecond or longer pulses.

\section{References}

1. J. H. Frank et al, Journ. of Microscopy 227 (2007) p. 203

2. A. D. Aguirre et al, Opt. Express 14 (2006) p. 1245

3. P. Falk et al, Opt. Letters (2008) Early posting

4. D.-I. Yeom et al, Opt. Letters 32 (2007) p. 1644

5. P. S. Westbrook et al, IEEE OFC/NFOEC (2007) OTuJ5

6. Y. Deng et al, Opt. Letters 30 (2005) p. 1234

7. W. J. Wadsworth et al, Opt. Express 12 (2004) p. 299

8. K. M. Hilligsøe et al, Opt. Express 12 (2004) p. 1045 